\title{
The Function of Gesture in Architectural-Design-Related Spatial Ability.
}

\section{Conference Paper}

\section{Author(s):}

Park, Yesol; Brösamle, Martin; Hölscher, Christoph

Publication date:

2020

Permanent link:

https://doi.org/10.3929/ethz-b-000460631

\section{Rights / license:}

In Copyright - Non-Commercial Use Permitted

\section{Originally published in:}

Lecture Notes in Computer Science 12162, https://doi.org/10.1007/978-3-030-57983-8_24

\section{Funding acknowledgement:}

676063 - Deictic Communication - A Multidisciplinary Training (EC) 


\title{
The Function of Gesture in Architectural-Design-Related Spatial Ability
}

\author{
Yesol Park ${ }^{1}$, Martin Brösamle ${ }^{1}$, and Christoph Hölscher ${ }^{1,2}$ \\ ${ }^{1}$ Chair of Cognitive Science ETH Zürich, Zürich, Switzerland \\ ${ }^{2}$ Future Cities Laboratory, Singapore-ETH Center, Singapore \\ parkye@ethz.ch
}

\begin{abstract}
The architectural design process requires high levels of spatial ability. A battery of spatial ability tests specifically for architects is currently being developed by a team of educational psychologists and architectural scholars. The present study uses these test materials to investigate how gestures support architects' mental spatial visualization. We conducted laboratory experiments to test two types of spatial visualization: mental cutting and mental transformation. We examined three aspects of the cognitive role of architects' gestures in spatial visualization: (1) the beneficial effects of gestures on spatial visualization test performance, (2) the relations between gesture frequency and task difficulty, and (3) the relations between gesture frequency and the type of mental imagery. Our data analysis results did not support the general hypothesis that architects' spontaneous gestures have a beneficial effect on spatial visualization test performance. However, there are noteworthy differences in the results when we look separately into the data from the two different task types, mental cutting and mental transformation. Most importantly, the frequency of gestures is significantly higher in the task that requires spatial imagery. This result could be explained by understanding the types of imagery underlying mental activities in solving the two tasks. We assume that spatial imagery involves more motor simulation compared to object imagery, and that this was reflected in the significant difference in the gesture frequencies observed.
\end{abstract}

Keywords: Spatial ability for architecture, Hand gesture, Spatial imagery, Object imagery, Motor simulation.

\section{Introduction}

\subsection{Motivation and Background}

The Finnish architect Pallasmaa [28] remarked that hands are important aids for architects in understanding situations and problems represented in drawings and other graphic media. Research has continued to investigate the use of gestures in architectural design [7]. The communicative function of gesture in face-to-face architectural design meetings seems obvious [34]. However, many questions about hand movements that 
architects spontaneously make while solving spatial problems remain unanswered. This study investigates how gestures support architects' abilities for mental spatial visualization. In an experiment we used psychometric tests developed specifically for architects in order to examine spontaneous gestures that occurred during the silent thinking process while solving the tasks.

Spatial ability has been defined as "the capacity to understand, reason, and remember the spatial relations among objects or space" [30]. It has been argued that spatial ability is crucial to success in science, technology, engineering, and mathematics (STEM) domains that involve the use of spatial skills $[21,31,33]$. Its implications for education have been increasingly highlighted. Therefore, investigating how to enhance one's spatial ability has become one of the focus topics for cognitive psychology research [10, 27]. Research in other disciplines has shown that it is possible to capture domain-specific spatial ability [13, 29]. For example, Berkowitz and Stern [2] measured specific spatial abilities that capture the mental processes of mechanical engineering students. Shipley, Tikoff, Ormand, and Manduca [29] developed a new test that consists of unique spatial problems in geology.

The present study is based on the assumption that architectural design, a domain that deals principally with spatial problems, also requires high levels of spatial ability. A set of spatial ability tests for architects (SATAs) have been developed by our colleagues, a team of educational psychologists and architectural scholars from ETH Zürich and ZHAW Winterthur in Switzerland [13]. This set of tests intends to differentiate architects from experts in other disciplines by characterizing spatial skills that are particularly relevant to the architectural design process.

Recent cognitive science research has suggested that spatial ability should be considered not as a unitary concept but as consisting of several different factors $[5,25,26]$. For example, Lohman [25] classifies three major factors: spatial visualization, spatial relations, and spatial orientation. Other scholars define spatial visualization as an ability to mentally manipulate 2-D or 3-D spatial figures [30]. Blajenkova, Kozhevnikov, and Motes's work [3] further assorts two types of imagery in mental visualization: object imagery refers to representations of individual objects' precise form, size, and shape whereas spatial imagery concerns spatial relations amongst objects or movements of objects including complex spatial transformations [12, 16, 18].

Amongst other spatial ability factors, spatial visualization has often been investigated with particular focus on the use of gesture. For example, a study by Chu and Kita [10] tested whether gestures improve participants' performances in mental rotation tasks. Their results indicate that gestures enhance the mental computation of spatial transformations when solving spatial visualization problems. Several gesture studies have reported a close relationship between mental imagery, motor actions, and perception $[9,14,19,20]$. Hostetter and Alibali $[19,20]$ proposed a theoretical framework that explains how spontaneous gestures are linked to the activation of perception and motor activity: The thought process that involves visuospatial imagery requires an activation of the motor system so that gestures arise automatically and reflect the motor activity. Congruent with this argument, several studies [e.g. 6, 22, 32] have examined the role of gestural actions that can facilitate thought directly by arousing spatial-motor imagery. 
In the present study, we aim to investigate the beneficial effects of architects' spontaneous gestures in spatial visualization problem solving. Moreover, we expect that architects spontaneously deploy gestures more frequently when the spatial visualization tasks involve more motor imagery.

\subsection{Present study}

To connect gesture activity to specific types of imagery in mental visualization, our study focused on a subset of the SATAs on two particular types of spatial visualization tasks: mental cutting tasks and mental transformation tasks. The selection was made based on our observations during piloting that architecture student participants produced hand gestures spontaneously for these two particular task types. Considering the imagery classification of Blajenkova et al. [3], we assume that the mental activity engaged in the mental cutting test is closely related to object imagery whereas the activity to solve the mental transformation test involves spatial imagery. The two test types are further elaborated in section 2.4.

The goal of the present study is to investigate how and to what degree gestures support architects' mental visualization. We examine three aspects of the cognitive role of architects' gestures in spatial visualization problem solving: (1) the beneficial effect of gestures on spatial visualization test performance, (2) the relation between gesture frequency and task difficulty, and (3) the relation between the frequency of gesture and the type of mental imagery involved in the task.

Regarding the first point (1), we aim to examine the beneficial influence of gestures on spatial visualization problem solving. We predict that spontaneous gestures increase architects' test performance in spatial visualization tasks by enhancing computation for mental imagery. Following the same rationale, we expect that gesturing helps participants to solve the spatial visualization tasks faster. However, these beneficial effects would not appear in trials in which gestures are not allowed:

Hypothesis 1.1. Across all tasks, the accuracy (the proportion of correct answers among all items) is higher in the with-gesture condition than in the without-gesture condition.

Hypothesis 1.2. Across all tasks, completion time is longer in the without-gesture condition than in the with-gesture condition.

In accordance with hypothesis 1.1, within the with-gesture trials only, we should be able to observe a negative correlation between the error rate (the proportion of trials with an incorrect response) and the gesture frequency (the number of hand movements produced per task). Regarding the relation between gesture frequency and task difficulty, point (2), we investigate whether more difficult spatial visualization problems trigger more gestures. We hypothesized that harder tasks may result in a higher frequency of gesture than the easy ones, given that participants gesture as often as they need to. We assume that a task's difficulty can be gauged by the error rate and the response time to complete tasks: 
Hypothesis 2.1. Within the with-gesture trials only, we expect a negative correlation between the error rate (the proportion of trials with an incorrect response) and the gesture frequency.

Hypothesis 2.2. Within the with-gesture trials only, we expect a positive correlation between completion time and gesture frequency.

Regarding the relation between the frequency of gesture and the type of mental imagery, point (3), we investigate whether gestures occur in connection with a particular type of imagery in mental visualization. We hypothesized that gestures would occur more frequently when the spatial visualization task involves more motor imagery. We expect the mental transformation test to involve more motor imagery than the mental cutting test:

Hypothesis 3.1. The frequency of gesture is higher in the mental transformation tasks than in the mental cutting tasks.

\section{Method}

A comparison between the two different conditions, with-gesture and without-gesture, tests hypotheses 1.1 and 1.2. To examine how the gesture behavior differs between task types we also used two types of tests: mental cutting and mental transformation. A comparison of their effects tests hypotheses $2.1,2.2$, and 3.1 .

\subsection{Design}

The experiment is based on a $2 \times 2 \times 4$ mixed design, with a within-participants factor with two conditions, with-gesture and without-gesture, and a within-participants factor of two types of spatial visualization tests, mental cutting and mental transformation. Furthermore, we systematically varied and balanced the order of the four combinations of test type and gesture condition as a between-participants factor to counter potential statistical bias from task order and carry-over effects. Each participant was randomly assigned to one of four groups: A, B, C, and D. Groups A and C started in the with-gesture condition and groups B and D started in the without-gesture condition. The experiment was split into four blocks. Each block has six test items, and each block is under either the with-gesture or the without-gesture condition. Table 1 summarizes the procedure for all four groups. 
Table 1. Experimental design: the division of four groups of participants and the assigned tasks under with-gesture and without-gesture instruction conditions

\begin{tabular}{|l|l|l|l|l|}
\hline & \multicolumn{1}{|c|}{ Group A } & \multicolumn{1}{c|}{ Group B } & \multicolumn{1}{c|}{ Group C } & \multicolumn{1}{c|}{ Group D } \\
\hline Block 1 & $\begin{array}{l}\text { Mental cutting } \\
\text { test with } \\
\text { gesture }\end{array}$ & $\begin{array}{l}\text { Mental cutting } \\
\text { test without } \\
\text { gesture }\end{array}$ & $\begin{array}{l}\text { Mental } \\
\text { transformation } \\
\text { test with gesture }\end{array}$ & $\begin{array}{l}\text { Mental } \\
\text { transformation } \\
\text { test without } \\
\text { gesture }\end{array}$ \\
\hline Block 2 & $\begin{array}{l}\text { Mental } \\
\text { transformation } \\
\text { test with } \\
\text { gesture }\end{array}$ & $\begin{array}{l}\text { Mental } \\
\text { transformation } \\
\text { test without } \\
\text { gesture }\end{array}$ & $\begin{array}{l}\text { Mental cutting } \\
\text { test with gesture }\end{array}$ & $\begin{array}{l}\text { Mental cutting } \\
\text { test without } \\
\text { gesture }\end{array}$ \\
\hline Block 3 & $\begin{array}{l}\text { test without } \\
\text { gesture }\end{array}$ & $\begin{array}{l}\text { Mental cutting } \\
\text { test with gesture }\end{array}$ & $\begin{array}{l}\text { Mental } \\
\text { transformation } \\
\text { test without } \\
\text { gesture }\end{array}$ & $\begin{array}{l}\text { Mental } \\
\text { transformation } \\
\text { test with gesture }\end{array}$ \\
\hline Block 4 & $\begin{array}{l}\text { Mental } \\
\text { transformation } \\
\text { test without } \\
\text { gesture }\end{array}$ & $\begin{array}{l}\text { Mental } \\
\text { transformation } \\
\text { test with gesture }\end{array}$ & $\begin{array}{l}\text { Mental cutting } \\
\text { test without } \\
\text { gesture }\end{array}$ & $\begin{array}{l}\text { Mental cutting } \\
\text { test with gesture }\end{array}$ \\
\hline
\end{tabular}

\subsection{Measures and analysis}

Three dependent variables were measured: (1) Accuracy, the proportion of correct answers among all items in a block; (2) completion time, the time that participants took to complete each block; and (3) frequency of gesture, the number of gestures that occurred while solving the task in the with-gesture condition.

A $t$-test accounted for differences in performance between the with-gesture and the without-gesture conditions (hypotheses 1.1 and 1.2). A Pearson correlation coefficient was calculated to analyze the connections between the task difficulty measures and gesture frequency (hypotheses 2.1 and 2.2). A paired $t$-test was conducted to compare the frequency of gesture mental cutting and mental transformation test types (hypothesis 3.1).

\subsection{Participants}

Fifty-six architecture students, 28 males and 28 females, from the Swiss Federal Institute of Technology in Zürich (ETH Zürich) participated in the experiment. Spatial ability is malleable, so we reasoned that it could improve with increasing level and duration of architecture education. For this reason, only third-year Bachelor and Master 
students were selected as participants. All participants had normal or corrected-to-normal vision.

\section{$2.4 \quad$ Tasks}

Mental cutting test. This test requires the visualization of cross-sections, which is a common activity in architectural design [13]. In each task, participants are presented with a 2-D perspective drawing of a 3-D object, which is to be cut with a plane. Participants are then asked to choose one correct resulting cross-section among five alternatives [8]. Fig. 1 shows one sample item of the mental cutting test and its answer.

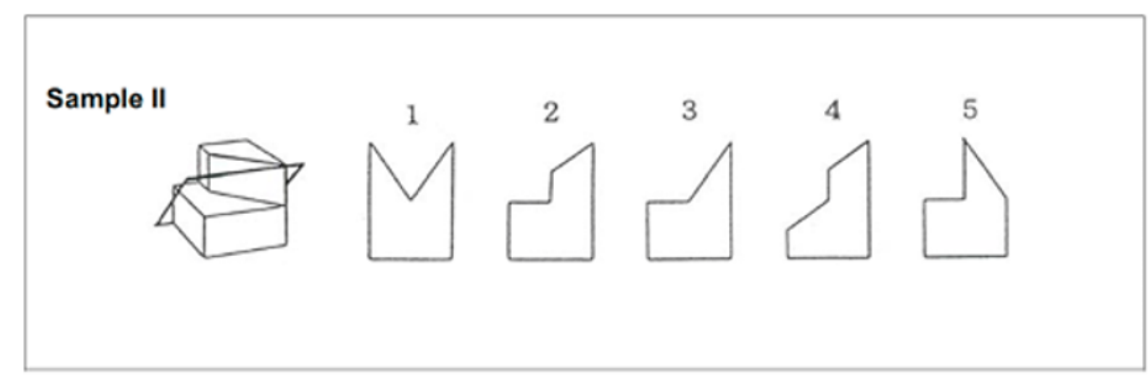

These figures show that No.3 is the correct answer choice for Sample Problem II.
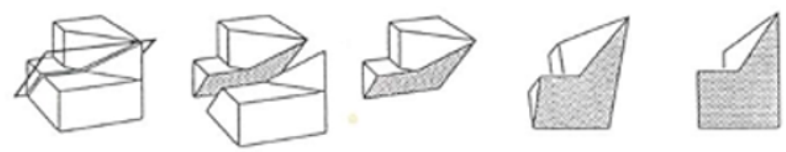

Fig. 1. Example of the mental cutting test

Mental transformation test. The SATAs mental transformation test is designed to evaluate architects' capacity to mentally modify 3 -D volumes and combine the transferred volumes together [13]. Each problem begins with a 3-D cube. Then it asks the participants to perform a set of transformations mentally according to a series of given instructions. Finally, participants then choose which of the four presented result candidates corresponds to the given transformations. An example of one mental transformation test item is shown in Figure 2. 


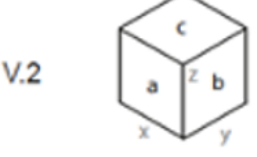

1. Extend the cube by half of its volume through (a). 2 . Cut the new body in half parallel to (c). 3 . Reduce the new volume by half through (b). 4. Rotate the new body $180^{\circ}$ over (z). Which of the following bodies did you get?
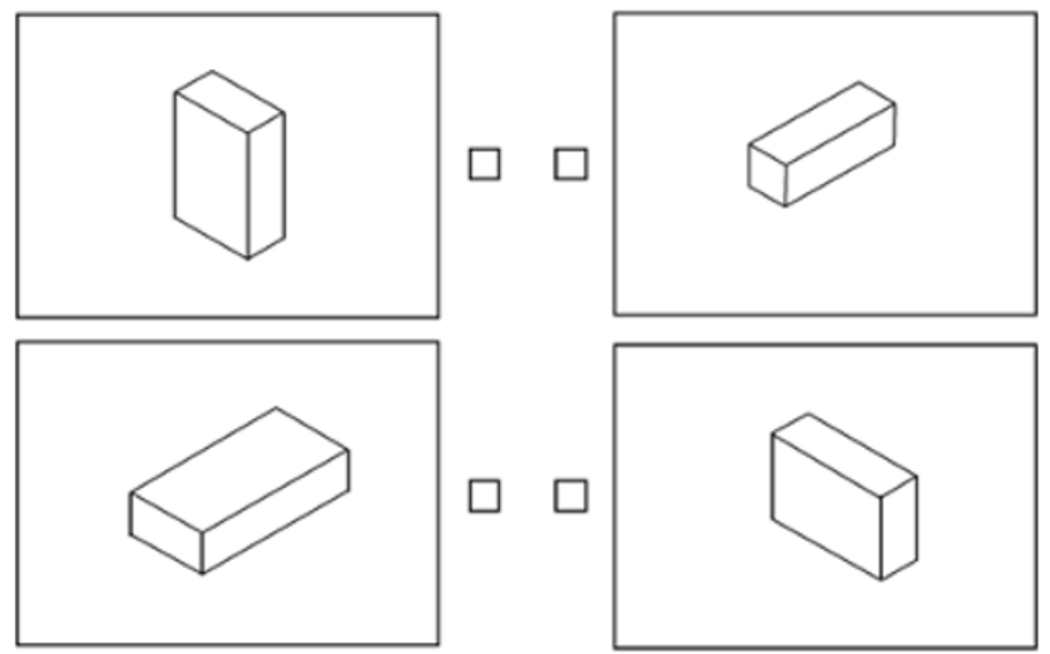

Fig. 2. Fig. 2. Example of the mental transformation test

\subsection{Procedure}

We tested each participant individually in a small room with one desk. They were asked to sit at the desk and to solve one task at a time. Each task was presented to them on a separate piece of A4 paper. For the with-gesture blocks, participants were told that "you can interact freely with printed test materials while you solve the test items". For the without-gesture blocks, participants were told to "put your hands under the desk and keep your hands still while solving the tasks". The instruction never mentioned "gesture" explicitly. We suspected that time pressure might suppress spontaneous gestures, so we told our participants that accuracy was more important than speed. While they solved the problems, a camera aimed at the desk to capture any gestures they made as well as their verbalizations.

\section{Result}

The 56 participants solved 16 of the 24 problems correctly on average $(S D=3.36)$. The average time to complete each problem was 36.17 seconds $(S D=17.75)$. 


\subsection{Test performance between with-gesture and without-gesture}

We examined the beneficial influence of gestures on solving spatial visualization problems. A paired samples $t$-test compares the accuracy (the proportion of correct answers among all items) in the with-gesture and the without-gesture conditions. Table 2 shows the descriptive statistics and $t$-test results. The left side of Table 2 shows means $(M)$ and standard deviations $(S D)$ for the accuracy and completion times in the two conditions and the two task types. The $t$-test result values on the right side of Table 2 are the degrees of freedom $(d f)$; the calculated $t$ value $(t)$ and $p$-value; Cohen's $d$ effect size. For the mental cutting test, there was no significant difference in accuracy $(t(55)=.36$, $p=.72, d=.06)$ between the with-gesture condition $(M=67.53, S D=24.61)$ and the without-gesture condition $(M=66.03, S D=21.53)$. Also, for the mental transformation test, the study results did not find a significant difference in accuracy $(t(55)=-.09, p=$ $.96, d=.02)$ between the with-gesture condition $(M=66.37, S D=18.93)$ and the without-gesture condition $(M=66.07, S D=17.68)$.

Moreover, there was no significant difference for completion time. The result from the mental cutting test in with-gesture condition $(M=35.87, S D=18.23)$ and withoutgesture condition $(M=31.89, S D=19.65)$ did not find a significant difference in the completion time $(t(55)=1.09, p=.28, d=.21)$. Likewise, the results from the mental transformation test did not show a significant difference in the completion time $(t(55)$ $=-.05, p=.93, d=.01)$, although the with-gesture condition $(M=38, S D=14.93)$ took slightly longer than the without-gesture condition $(M=37.82, S D=25.58)$.

Table 2. Paired-samples $t$-test results comparing the accuracy and the completion time in the with-gesture and the without-gesture conditions.

\begin{tabular}{|c|c|c|c|c|c|c|c|c|c|}
\hline & & \multicolumn{4}{|c|}{ Descriptive data } & \multicolumn{4}{|c|}{$t$-test } \\
\hline & & \multicolumn{2}{|c|}{ With gesture } & \multicolumn{2}{|c|}{$\begin{array}{l}\text { Without } \\
\text { gesture }\end{array}$} & & & & \\
\hline Variable & Task type & $M$ & $S D$ & $M$ & $S D$ & $d f$ & $t$ & $\begin{array}{c}p- \\
\text { value }\end{array}$ & $\begin{array}{l}\text { Effect } \\
(d)\end{array}$ \\
\hline \multirow[b]{2}{*}{$\begin{array}{c}\text { Accuracy } \\
(\%)\end{array}$} & Mental cutting & 67.53 & 24.61 & 66 & 21.53 & 55 & .36 & .72 & .06 \\
\hline & $\begin{array}{c}\text { Mental } \\
\text { Transformation }\end{array}$ & 66.37 & 18.93 & 66.1 & 17.68 & 55 & -.09 & .96 & .02 \\
\hline \multirow{2}{*}{$\begin{array}{l}\text { Completion } \\
\text { time } \\
\text { (seconds) }\end{array}$} & Mental cutting & 35.87 & 18.23 & 31.9 & 19.65 & 55 & 1.09 & .28 & .21 \\
\hline & $\begin{array}{c}\text { Mental } \\
\text { transformation }\end{array}$ & 38 & 14.93 & 37.8 & 25.58 & 55 & -.05 & .93 & .01 \\
\hline
\end{tabular}

\subsection{Gesture frequency and task difficulty for the with-gesture condition}

The Pearson correlation coefficient was conducted to identify any relationship between the gesture frequency (only within the with-gesture condition) and the error rate. Results did not show a significant relation between the gesture frequency and the error 
rate, neither for the mental cutting $(r(55)=-.07, p=.61)$ nor for the mental transformation $(r(55)=.01, p=.93)$.

Furthermore, we sought a relationship between the gesture frequency and the response time to complete the tasks. For the mental cutting test, the Pearson correlation test did not find a significant relation between the gesture frequency and the response time $(r(55)=.02, p=.89)$. However, for the mental transformation, the gesture frequency was found to be correlated with the response time $(r(55)=.346, p=.009)$.

Table 3. summarizes the Pearson correlation coefficient results. The test values in Table 3 include the degrees of freedom $(d f)$; the calculated $r$ value $(r)$ and $p$-value.

\begin{tabular}{|c|c|c|c|c|}
\hline Variables & Task type & $d f$ & $r$ & $p$-value \\
\hline \multirow{2}{*}{$\begin{array}{c}\text { Gesture frequency and } \\
\text { error rate }\end{array}$} & Mental cutting & 55 & -.07 & .61 \\
\cline { 2 - 5 } & Mental transformation & 55 & .01 & .93 \\
\hline \multirow{2}{*}{$\begin{array}{c}\text { Gesture frequency and } \\
\text { response time }\end{array}$} & Mental cutting & 55 & .02 & .89 \\
\cline { 2 - 5 } & Mental transformation & 55 & .35 & .01 \\
\hline
\end{tabular}

\subsection{Gesture frequency and test type within the with-gesture condition}

We aimed to examine whether the gestures particularly occur in connection with a certain type of visuospatial imagery in mental visualization. A paired-samples $t$-test was conducted to compare the gesture frequency in the mental cutting and mental transformation test conditions. The left side of Table 4 presents the means $(M)$ and standard deviations $(S D)$ for the gesture frequency for the two test types. The right side of Table 4 shows the results of a paired-samples $t$-test comparing the means. Values displayed in the right side of Table 3 are the degrees of freedom ( $d f)$; the calculated $t$ value $(t)$, and the $p$-value; Cohen's $d$ effect size. The with-gesture trials exhibited significantly more gestures $(t(55)=-8.33, p<.001 ; d=1.98)$ in mental transformation $(M=113.25$, $S D=37.22)$ compared to the mental cutting $(M=47, S D=29.21)$ with an effect size of $d=1.98$, hence exceeding Cohen's [11] convention for a large effect $(d=.80)$.

Table 4. Paired-samples $t$-test results comparing the gesture frequency in the mental cutting and mental transformation tests.

\begin{tabular}{|c|c|c|c|c|c|c|c|c|}
\hline \multirow[b]{3}{*}{ Variable } & \multicolumn{4}{|c|}{ Descriptive data } & \multicolumn{4}{|c|}{$t$-test } \\
\hline & \multicolumn{2}{|c|}{$\begin{array}{l}\text { Mental } \\
\text { cutting }\end{array}$} & \multicolumn{2}{|c|}{$\begin{array}{c}\text { Mental } \\
\text { transformation }\end{array}$} & \multirow[b]{2}{*}{$d f$} & \multirow[b]{2}{*}{$t$} & \multirow[b]{2}{*}{$p$-value } & \multirow[b]{2}{*}{$\begin{array}{l}\text { Effect } \\
(d)\end{array}$} \\
\hline & $M$ & $S D$ & $M$ & $S D$ & & & & \\
\hline $\begin{array}{l}\text { Gesture } \\
\text { frequency }\end{array}$ & 47 & 29 & 113 & 37 & 55 & -8.33 & $<.001$ & 1.98 \\
\hline
\end{tabular}




\section{Discussion}

Our hypothesis, that architects' spontaneous gestures have a beneficial effect on spatial visualization test performance, was not confirmed. When we look separately into the data from the two different task types there are, however, interesting differences in the results, mental cutting and mental transformation. For the mental transformation task there was a significant positive correlation between gesture frequency and response time. For the mental cutting task, by contrast, this correlation was not found. Moreover, in the results from testing hypothesis 3.1 , we found that participants produced significantly more gestures during the mental transformation task (113.25 gestures out of 6 trials) than during the mental cutting task (47 gestures out of 6 trials). For the gesture effect on accuracy such difference between the task types was not observed. When analyzing results for the testing of hypothesis 1.1, we did not find significant differences in participants' accuracy between the with-gesture condition and the without-gesture condition for both task types. In addition, when testing hypothesis 1.2, we did not find direct evidence that gesturing helps participants to solve both types of tasks faster. If gestures do not particularly enhance architects' test performance, why did they still produce a large number of spontaneous gestures? And why was there a significant difference in the gesture frequency between the two types of spatial visualization, the mental cutting and mental transformation?

Several studies [17, 19, 20,32] have proposed that gestures arise from perceptual and motor simulations that underlie mental imagery. This argument could explain those results in our study that consider the relationship between gesture frequency, task types, and duration to complete the tasks. Hostetter and Alibali [20] argue that the amount of active processing differs depending on the type of imagery. Revisiting the imagery classification of Blajenkova et al. [3], we assume that gesturing might be less engaged in object imagery that concerns objects' spatial quantities, such as size and shape. On the flip side, spontaneous gestures could be expected to arise more for spatial imagery which concerns spatial relations, movement and transformation of spatial figures. With the additional assumption that spatial imagery involves more motor simulation compared to object imagery, we would suspect that motor simulation (that underlies spatial imagery) is strongly involved in solving the mental transformation task, but much less in solving the mental cutting task. We suspect this was reflected in the significant differences in the gesture frequencies of the two task types. Consequently, the mental transformation tasks in our experiment can be assumed to require more active processing of motor imagery, which elicited more gestures. By comparison, the mental cutting tasks required relatively passive processing of motor imagery and thus evoked fewer gestures. Furthermore, we speculate that the mental transformation task involves many more imagined movements than the mental cutting task. This might be another reason that there are both more gestures and larger response times in the mental transformation task in addition to the distinction between different types of imagery in the different tasks.

Previous studies $[4,17]$ have reported that gestures can aid thinking by reducing the demand on working memory. This would be in line with the assumption that the mental transformation task in our study required the activation of working memory processes, 
and that this caused higher frequencies of gestures as well as longer response times. Solving the mental transformation test requires multiple manipulations of mental 3-D objects. It involves mental maintenance of information about the motion of objects that is essential to inferring the final form [cf. 17]. During this process, the maintenance of earlier information may compete with processing demands and require working memory $[1,15,17,24]$. In this situation, gestures might help to reduce the demand for information maintenance. Therefore, it can be suggested that participants gestured more often to relieve high working memory demand in mental transformation tasks. Altogether, we believe that participants in our study were able to be engaged more deeply in spatial understanding and reasoning with the physical movement of gesture production. This led them to take longer time while solving tasks with gesturing. Apart from gestures' direct beneficial effect on increasing the task solving scores, we expect that gesturing aids architect's mental visualization especially when the task strongly involves motor simulation.

Our study results did not show direct evidence that gestures increase performance in mental spatial visualization involved in architectural design thinking. For example, the analysis of testing hypothesis 2.2 found that more gestures correlate to longer task duration. This result suggests that gestures do not support either task accuracy or task efficiency. In future studies, it would be interesting to investigate further why gestures do not decrease the time it takes to solve the task, but actually increase it.

Even though our hypotheses on the role of gesture in task accuracy and task efficiency are not supported, it would be premature to conclude purely from these results that gesture does not have any cognitive benefits for the spatial ability of architects. The present study focused only on gestures that occurred in the absence of speech, termed co-thought gestures [10]. It would be interesting to examine the effects of instructions to think aloud. Several studies $[17,19]$ contend that gestures will be more prevalent when people activate motor simulations along with speech. Chu and Kita [10] investigated how the formulation of instructions influences gesturing behavior. They compared three participant groups with different gesture instructions for spatial problem solving: a gesture-encouraged group, a gesture-allowed group, and a gesture-prohibited group. Participants in the gesture-encouraged group were instructed to move their hands in a specific way that was expected to help solve given spatial problems [10]. The gesture-encouraged group performed better than the other two groups. This finding implies that instructions can influence gestures in the performance of spatial visualization. We hence conclude that it is important to design gesture instructions carefully in future studies.

\section{Conclusion and future study}

The main research aim of our study was to better understand how and to what degree gestures support architects' mental spatial visualization. Our experiment tested whether gestures can enhance architects' spatial visualization test performance. We used spatial ability test materials specialized for architects and examined gestures produced 
spontaneously during the silent thinking process. We looked at two types of spatial visualization, which have been broken down into single test items resembling elementary aspects of the architectural design process [13]. Our study did not provide evidence that gestures enhance the accuracy of mental visualization task performance. However, we speculate participants being engaged more deeply in spatial reasoning when they are allowed to move their hands freely. Moreover, our study results suggest that architects produce more gestures when solving tasks that involve spatial-motor imagery compared to tasks that involve object imagery or visual imagery to solve spatial quantity and pattern recognition problems.

The experiment materials and tasks used in this study were not typical of actual architecture design. Psychometric tests are mainly designed to study the individual elements of mental operations separately. By contrast, real architectural design activities often combine several mental processes simultaneously [13]. In a future study, we will use actual architectural drawings such as floor plans and sections to investigate the role of gestures in a more realistic architectural design context. In particular, we will further investigate how spatial-motor imagery is involved in the actual architecture design process and how this is facilitated by architects' gestures.

\section{Acknowledgment}

The research was partly conducted at the Future Cities Laboratory at the SingaporeETH Centre, which was established collaboratively between ETH Zurich and Singapore's National Research Foundation (FI 370074016) under its Campus for Research Excellence and Technological Enterprise programme. Yesol Park is funded by the DComm grant (EU H2020 ITN Marie Skłodowska-Curie Actions; grant agreement 676063).

\section{References}

1. Baddeley, A.D.: Working Memory. Oxford: Oxford University Press (1986).

2. Berkowitz, M., Stern, E.: Which Cognitive Abilities Make the Difference? Predicting Academic Achievements in Advanced STEM Studies. Journal of Intelligence 6(4) (2018).

3. Blajenkova, O., Kozhevnikov, M., Motes, M. A.: Object-Spatial Imagery: A New Self-Report Imagery Questionnaire. Applied Cognitive Psychology 20(2), 239-263 (2006).

4. Carlson, R. A., Avraamides, M. N., Cary, M., Strasberg, S.: What Do the Hands Externalize in Simple Arithmetic? Journal of Experimental Psychology: Learning, Memory, and Cognition 33(4), 747-756 (2007).

5. Carroll, J., B.: Human Cognitive Abilities: A Survey of Factor-Analytic Studies. Cambridge; New York: Cambridge University Press (1993).

6. Cartmill, E. A., Beilock, S. L., Goldin-Meadow, S.: A Word in the Hand: Human Gesture Links Representations to Actions. Philosophical Transactions of the Royal Society, B, 367, 129-143 (2012).

7. Cash, P., \& Maier, A.: Prototyping with your Hands: The Many Roles of Gesture in the Communication of Design Concepts. Journal of Engineering Design 27(1-3), 118-145 (2016).

8. CEEB: Special Aptitude Test in Spatial Relations. USA (1939). 
9. Chu, M., Kita, S.: Spontaneous Gestures During Mental Rotation Tasks: Insights into the Micro Development of the Motor Strategy. Journal of Experimental Psychology: General 137, 706-723 (2008).

10. Chu, M., Kita, S.: The Nature of Gestures' Beneficial Role in Spatial Problem Solving. Journal of Experimental Psychology: General 140, 102-116 (2011).

11. Cohen J.: Statistical Power Analysis for the Behavioral Sciences. New York, NY: Routledge Academic (1988).

12. Farah, M. J., Hammond, K. M., Levine, D. N., Calvanio, R.: Visual and Spatial Mental Imagery: Dissociable Systems of Representations. Cognitive Psychology 20, 439-462. (1988).

13. Gerber, A., Berkowitz, M., Emo, B., Kurath, S., Hölscher, C., Stern, E.: Does Space Matter? A Cross-Disciplinary Investigation upon Spatial Abilities of Architects, in Research Culture in Architecture. Cross-Disciplinary Collaboration, eds. Cornelie Leopold, Christopher Robeller, Ulrike Weber Basel: Birkhäuser Verlag (2019).

14. Goldin-Meadow, S., Beilock, S. L.: Action's Influence on Thought: The Case of Gesture. Perspectives on Psychological Science 5, 664-674 (2010).

15. Grüter, T., Grüter, M., Bell, V., Carbon, C. C.: Visual Mental Imagery in Congenital Prosopagnosia. Neuroscience letters 453, 135-140 (2009).

16. Hegarty, M., \& Kozhevnikov, M.: Types of Visual-Spatial Representations and Mathematical Problem Solving. Journal of Educational Psychology 91, 684-689 (1999).

17. Hegarty, M., Mayer, S., Kriz, S., Keehner, M.: The Role of Gestures in Mental Animation, Spatial Cognition \& Computation 5(4), 333-356 (2005).

18. Heuer, F., Fischman, D., Reisberg, D.: Why Does Vivid Imagery Hurt Colour Memory? Canadian Journal of Psychology 40, 161-175 (1986).

19. Hostetter, A. B., Alibali, M. W.: Gesture as Simulated Action: Revisiting the Framework. Psychonomic Bulletin \& Review 26(3), 721-752 (2019).

20. Hostetter, A. B., Alibali, M. W.: Visible Embodiment: Gestures as Simulated Action. Psychonomic Bulletin \& Review 15(3), 495-514 (2008).

21. Humphreys, L. G., Lubinski, D., Yao, G.: Utility of Predicting Group Membership and the Role of Spatial Visualization in Becoming an Engineer, Physical Scientist, or Artist. Journal of applied psychology 78(2), 250 (1993).

22. Kang, S. Tversky, B., Black, J. B.: From Hands to Minds: How Gestures Promote Action Understanding. In: Proceedings of the 34th Annual Conference of the Cognitive Science Society, pp. 551-557. Austin TX: Cognitive Science Society (2012).

23. Kang, S., Tversky, B., Black, J.: Coordinating Gesture, Word, and Diagram: Explanations for Experts and Novices. Spatial Cognition \& Computation, 15 (2015).

24. Logie, R. H.: Visuo-spatial Working Memory. Hove: Lawrence Erlbaum Associates (1995).

25. Lohman, D. F.: Spatial Ability: A Review and Reanalysis of the Correlational Literature. (Technical Report No. 8). Stanford, CA: Aptitude Research Project, School of Education, Stanford University (1979).

26. McGee, M. G.: Human Spatial Abilities: Psychometric Studies and Environmental, Genetic, Hormonal, and Neurological Influences. Psychological Bulletin 86(5), 889-918 (1995).

27. Newcombe, N., Shipley, T.: Thinking About Spatial Thinking: New Typology, New Assessments (2015).

28. Pallasmaa, J.: The Thinking Hand Existential and Embodied Wisdom in Architecture, Chichester, United Kingdom, John Wiley and Sons Ltd (2009).

29. Shipley, T., Tikoff, B., Ormand, C., Manduca, C.: Structural Geology Practice and Learning, from the Perspective of Cognitive Science. Journal of Structural Geology 54, 72-84 (2013).

30. Sorby, S., A.: Developing 3-D Spatial Visualization Skills. Engineering Design Graphics Journal 63, 21-32 (1999). 
31. Stieff, M., Lira, M. E., Scopelitis, S. A.: Gesture Supports Spatial Thinking in STEM, Cognition and Instruction 34(2), 80-99 (2016).

32. Tversky, B., Jamalian, A., Giardino, V., Kang, S., Kessell, A.: Comparing Gestures and Diagrams, 10th International Gesture Workshop, Tilburg Netherlands (2013).

33. Uttal, D., H., Cheryl, A., C.: Spatial Thinking and STEM Education: When, Why and How. Psychology of learning and motivation 57, 147-181 (2012).

34. Visser, W.: The Function of Gesture in an Architectural Design Meeting (ch. 15). In J. McDonnell \& P. Lloyd (Eds.), R. Luck, F. Reid, \& N. Cross (Ass. Eds.), Designing. Analysing design meetings (pp. 269-284). London: Taylor \& Francis (2009). 